\title{
OVÍDIO, AMORES, II.12
}

TRADUZIDO POR DANIEL DA SILVA MOREIRA 


\title{
OVÍDIO, AMORES, II.12
}

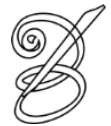 \\ Traduzido por: \\ Daniel da Silva MOREIRA \\ Doutorando em Letras - Estudos Literários \\ Universidade Federal de Juiz de Fora \\ Juiz de Fora, Minas Gerais, Brasil \\ moreiradsm@gmail.com
}

\section{Sobre o poema}

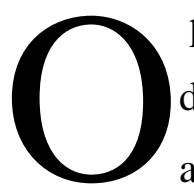

poema que apresento em tradução pertence aos Amores, de Ovídio (43 a.C. - 17/18

d.C.), coleção de elegias de temática amorosa dada a público por volta do ano de 16

a.C. e composta empregando o dístico elegíaco, um tipo de estrofe mínima da poesia antiga, formada por um hexâmetro e um pentâmetro. Entre os muitos aspectos e temas

176 amorosos tratados pelas elegias dos Amores, a II.12 é um poema de triunfo. Depois de vencidos os obstáculos que o separavam da amada, o amante comemora coroado com louros como aqueles dados aos generais vitoriosos e, à moda dos triunfos militares, relembra os estágios de sua conquista, fazendo passar em desfile uma recriação da narrativa de sua pequena guerra amorosa, em que exalta suas qualidades de soldado do exército de Cupido. Nesse sentido, a presente elegia pode ser tomada como exemplar de um dos topoi mais frequentes do código elegíaco, a militia amoris, "nela, as virtudes atribuídas aos soldados são transferidas aos amantes"ii (MILLER, 2012, p. 61, tradução minha). Em minha tradução desse poema - pelo que indicou minha pesquisa trata-se da primeira tradução brasileira -, faço a opção por empregar o verso, buscando assim dar, ainda que minimamente, algum agenciamento estético ao texto traduzido. Utilizei para a tradução versos alexandrinos e decassílabos para recriar, respectivamente, os hexâmetros e pentâmetros do dístico elegíaco. A escolha de versos relativamente curtos da tradição de língua portuguesa para traduzir versos em geral mais longos da reconhecidamente sintética língua latina implica, normalmente, na necessidade de empregar a elipse de palavras. Assim, para me adequar à métrica, omiti firma, no verso 03 ; superata, no 09 ; dissors, no 11; turpiter, no 20, iuste, no 22; sed, no 27; e suae militiae, no 28. A utilização de versos de medidas diferentes é uma tentativa de manter a claudicação do dístico elegíaco, característica marcante das elegias (NÉRAUDAU, 2005, p. 
XI). Ainda em relação ao dístico, procurei preservar uma de suas qualidades, a de, no interior do poema, constituir-se como uma unidade completa e, de certo modo, isolada, em que o poeta normalmente conclui seu pensamento.

\section{Tradução}

Ite triumphales circum mea tempora laurus!

Vicimus; in nostro est, ecce, Corinna sinu,

Quam uir, quam custos, quam ianua firma, tot hostes,

Seruabant, nequa posset ab arte capi.

Haec est praecipuo uictoria digna triumpho,

In qua, quaecumque est, sanguine praeda caret.

Non humiles muri, non paruis oppida fossis

Cincta, sed est ductu capta puella meo.

Pergama cum caderent bello superata bilustri,

Ex tot in Atridis pars quota laudis erat?

At mea seposita est et ab omni milite dissors

Gloria, nec titulum muneris alter habet;

Me duce ad hanc uoti finem, me milite ueni;

Ipse eques, ipse pedes, signifer ipse fui.

Nec casum fortuna meis inmiscuit actis;

Huc ades, o cura parte triumphe mea!

Nec belli est noua causa mea est. Nisi rapta fuisset

Tyndaris, Europae pax Asiaeque foret.

Femina siluestris Lapithas populumque biformem

Turpiter adposito uertit in arma mero.

Femina Troianos iterum fera bella mouere

Inpulit in regno, iuste Latine, tuo.

Femina Romanis, etiamnunc Vrbe recenti,
Vinde cingir-me a fronte, oh louros triunfais! Venci. E eis que em meu seio está Corina ${ }^{\text {iii }}$,

A que o marido, um guarda e a porta, rivais tantos,

Guardavam de ser pega em artimanhas.

De singular triunfo esta vitória é digna,

Pois nela a qualquer presa falta o sangue.

Nem baixos muros, nem cidades mal cercadas,

Mas ela, ao meu comando, foi tomada.

Quando, após guerra de dois lustros, caiu Pérgamo ${ }^{\text {iv }}$,

Qual parte em tanta honra coube aos Átridas ${ }^{v}$ ?

Mas minha glória está à parte à de qualquer

Soldado; esta honraria outro não tem.

Soldado e general, cheguei à meta; eu próprio

Cavaleiro, infante e porta-estandarte.

$\mathrm{E}$ a fortuna não pôs o acaso entre os meus atos;

Vem, oh triunfo nato em meu esforço!

Esta guerra nem é nova. Não raptassem

A tíndara ${ }^{\text {vi }}$ e Ásia e Europa paz teriam.

A mulher levou o povo biforme ${ }^{\text {vii }}$ e o lápita

Rude viii às armas, vinho puro servindo.

A mulher fez de novo os troianos moverem

Feroz guerra, oh Latino $^{\text {ix }}$, ao reino teu.

A mulher, a Urbe era recente, aos romanos 
Inmisit soceros armaque saeua dedit.

Vidi ego pro niuea pugnantes coniuge tauros;

Spectatrix animos ipsa iunenca dabat.

Me quoque, qui multos, sed me sine caede, Cupido

Iussit militiae signa mouere suae. ${ }^{x i}$
Seus sogros instigou, com cruéis armas ${ }^{\mathrm{x}}$.

Vi touros lutar por nívea esposa e a novilha

Própria, espectadora, os animava.

A mim, e a muitos, eu sem massacre, Cupido

Ordenou avançar seus estandartes.

\section{REFERÊNCIAS}

MILLER, Paul Allen. Tibullus. In: GOLD, Barbara K. (ed.). A Companion to Roman Love Elegy. Oxford: Wiley-Blackwell, 2012. P. 53-69.

NÉRADAU, Jean-Pierre. Introduction. In: OVIDE. Les Amours. Texte établi et traduit par Henri Bornecque. Paris: Les Belles Letres, 2005.

OVIDE. Les Amours. Texte établi et traduit par Henri Bornecque. Paris: Les Belles Letres, 2005.

iDaniel da Silva MOREIRA - Mestre em Letras: Estudos Literários (2011) pela Universidade Federal de Juiz de Fora (UFJF). Graduado em Letras: Língua Latina e Literatura Correspondente (2010) e em Letras: Língua Portuguesa e Literatura Correspondente (2007) pela mesma universidade.

Currículo Lattes Daniel da Silva Moreira. Disponivel em: http://lattes.cnpq.br/0587343464722458.

ii No original: "In it, virtues attributed to soldiers are transferred to the lovers (...)."

iii Ainda que não apareça em todas as elegias, Corina é encarnação da amada ideal para Ovídio nos Amores.

iv É comum Homero chamar assim a parte mais alta de Tróia.

${ }^{v}$ Menelau e Agamêmnon, filhos de Atreu.

vi Tíndaro é o pai adotivo de Helena de Tróia, aqui referida.

vii $\mathrm{O}$ povo biforme são os centauros, parte homens, parte cavalos. Eles foram convidados para as núpcias de Pirítoo, rei dos lápitas, e Hipodâmia, mas, desacostumados ao álcool, embebedaram-se, perderam o controle e tentaram raptar e violar a noiva, o que deu origem a uma grande batalha.

viii Os lápitas, na mitologia, eram da Tessália e, auxiliados por Teseu, derrotaram os centauros e os expulsaram de sua terra.

${ }^{\text {ix }}$ Foi Lavínia, filha do rei Latino, a causa o desentendimento entre Enéias e Turno, de que trata a segunda parte da Eneida.

x Alusão ao Rapto das Sabinas, episódio lendário da história de Roma em que a primeira geração de homens romanos teria conseguido esposas para si pelo rapto das filhas de seus vizinhos, os sabinos. Estes últimos, forçosamente tornados sogros dos romanos, reagiram ao acontecimento com uma violenta guerra.

xi Texto latino proveniente de: OVIDE. Les Amours. Texte établi et traduit par Henri Bornecque. Paris: Les Belles Letres, 2005. P. 96-98.

RECEBIDO EM: 29 de julho de 2016

ACEITO EM: 20 de setembro de 2016

PUBLICADO EM: Dezembro de 2016 